\title{
K45A mutation of RIPK1 results in poor necroptosis and cytokine signaling in macrophages, which impacts inflammatory responses in vivo
}

\author{
B Shutinoski ${ }^{1,2}$, NA Alturki ${ }^{1}$, D Rijal ${ }^{1}$, J Bertin ${ }^{3}$, PJ Gough ${ }^{3}$, MG Schlossmacher ${ }^{2}$ and S Sad ${ }^{*, 1}$
}

Receptor interacting protein kinase 1 (RIPK1) participates in several cell signaling complexes that promote cell activation and cell death. Stimulation of RIPK1 in the absence of caspase signaling induces regulated necrosis (necroptosis), which promotes an inflammatory response. Understanding of the mechanisms through which RIPK1 promotes inflammation has been unclear. Herein we have evaluated the impact of a K45A mutation of RIPK1 on necroptosis of macrophages and the activation of inflammatory response. We show that K45A mutation of RIPK1 results in attenuated necroptosis of macrophages in response to stimulation with LPS, TNF $\alpha$ and IFN $\beta$ in the absence of caspase signaling. Impairment in necroptosis correlated with poor phosphorylation of RIPK1, RIPK3 and reduced trimerization of MLKL. Furthermore, K45A mutation of RIPK1 resulted in poor STAT1 phosphorylation (at S727) and expression of RANTES and MIP-1 $\alpha$ following TNF-R engagement in the absence of caspase activation. Our results further indicate that in the absence of stimulation by pathogen-associated molecular patterns (PAMPs), cellular inhibitors of apoptotic proteins (cIAPs) prevent the K45-dependent auto-phosphorylation of RIPK1, leading to resistance against necroptosis. Finally, RIPK ${ }^{\mathrm{K} 45 \mathrm{~A}}$ mice displayed attenuated inflammatory response in vivo as they were significantly resistant against endotoxin shock, but highly susceptible against a challenge with Salmonella typhimurium. This correlated with reduced expression of IL-1 $\beta$ and ROS, and poor processing of caspase 8 by RIPK ${ }^{\text {K45A }}$ macrophages. Overall, these results indicate that K45 mediated kinase activity of RIPK1 is not only important for necroptosis but it also has a key role in promoting cytokine signaling and host response to inflammatory stimuli.

Cell Death and Differentiation (2016) 23, 1628-1637; doi:10.1038/cdd.2016.51; published online 3 June 2016

Apoptosis is considered as the predominant, programmed pathway of cell death; however, recently several pathways of regulated cell death have been shown to operate in cells that are considered highly inflammatory. ${ }^{1,2}$ Although apoptosis has a major role during fetal development, ${ }^{3}$ regulated necrotic cell death does not appear to influence fetal development. ${ }^{4}$ Interestingly, receptor interacting protein kinase 1 (RIPK1) deficiency cause embryonic lethality, suggesting a key role of RIPK1 in host survival. ${ }^{5}$ Besides the kinase activity, RIPK1 appears to have a scaffolding function, which may influence immune homeostasis. ${ }^{6,7}$ Depending on the interacting partners and posttranslational modifications, RIPK1 has a multifaceted role in cell signaling and cell survival. ${ }^{8}$ Following TNF-R1 signaling, RIPK1 transitions between pro-survival and pro-cell death signaling complexes. , $^{9,10}$

Necroptosis is a form of regulated necrosis of cells that operates in the absence of caspase activity ${ }^{9}$ and is initiated by the engagement of various TLRs or cytokine receptors. ${ }^{11}$ The first cardinal signaling step in necrosome signaling is the phosphorylation of RIPK1, which leads to RIPK1-RIPK3 interaction and phosphorylation of RIPK3. ${ }^{12}$ Although necroptotic signaling has been shown to be dependent on the homotypic interaction of RIPK1 and RIPK3, in certain cases RIPK3 can induce necroptosis independently of RIPK1. ${ }^{13}$ Indeed, the engagement of TNF-R, IFNAR1, TLR3 or TLR4 leads to phosphorylation of RIPK1 without induction of necroptosis. ${ }^{14}$

In contrast, phosphorylation of RIPK3 and the subsequent phosphorylation of the mixed lineage kinase-like (MLKL) protein is essential for induction of necroptosis. Phosphorylation of MLKL results in oligomerization of MLKL, which then translocate to cell membrane and disrupt cellular integrity by forming pores in the cell membrane. ${ }^{15-17}$

Irrespective of the relative protein interactions that lead to a regulated cell death, RIPK1 also interacts with various adaptor proteins. Through its RHIM domain, RIPK1 interacts with TRIF and DAI ${ }^{18,19}$ and consequently influences downstream signaling following ligation of pathogen-recognition receptors. In this report, we have used a kinase-dead mutant of RIPK1 (K45A mutation) ${ }^{20}$ and evaluated the impact on regulated cell death and cytokine signaling in macrophages and the consequent impact on inflammatory response in vivo.

${ }^{1}$ Department of Biochemistry, Microbiology and Immunology, Faculty of Medicine, University of Ottawa, Ottawa, ON K1H 8M5, Canada; ${ }^{2}$ Program in Neuroscience and Division of Neurology, The Ottawa Hospital, Ottawa, ON, Canada and ${ }^{3}$ Pattern Recognition Receptor Discovery Performance Unit, Immuno-Inflammation Therapeutic Area, GlaxoSmithKline, Collegeville, PA 19426, USA

${ }^{*}$ Corresponding author: S Sad, Department of Biochemistry, Microbiology and Immunology, Faculty of Medicine, University of Ottawa, 451 Smyth Road, Room 4139, Ottawa, Ontario K1H 8M5, Canada. Tel: +1 613562 5800; E-mail: subash.sad@uottawa.ca

Abbreviations: RIPK1, receptor interacting protein kinase 1; MLKL, mixed lineage kinase-like; Nec-1, necrostatin-1; ROS, reactive oxygen species; zVAD-fmk, $\mathrm{N}$-benzyloxycarbonyl-Val-Ala-Asp(O-Me) fluoromethyl ketone; MTT, 1-(4,5-dimethylthiazol-2-yl)-3,5-diphenylformazan; LPS, lipopolysaccharide; CFU, colony-forming units Received 11.8.15; revised 28.4.16; accepted 05.5.16; Edited by A Ashkenazi; published online 03.6.2016 
a

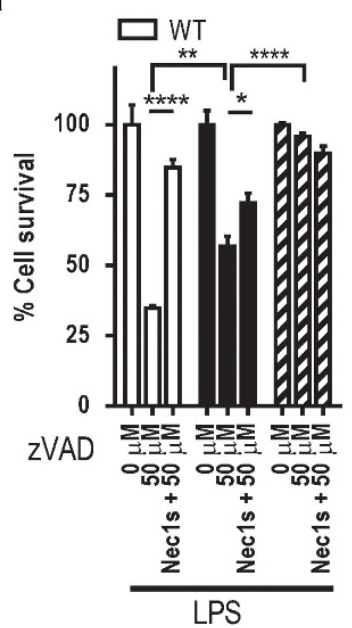

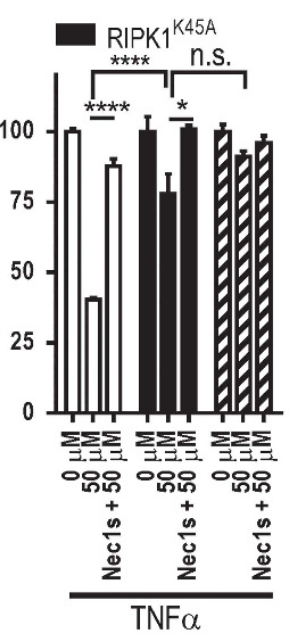

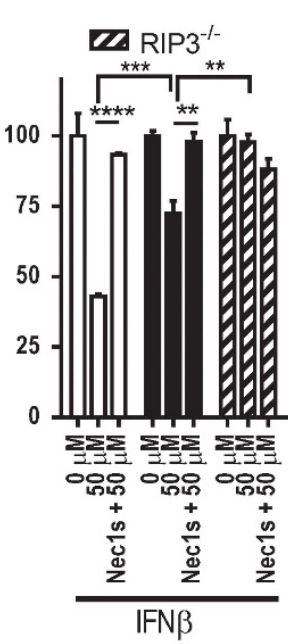

c

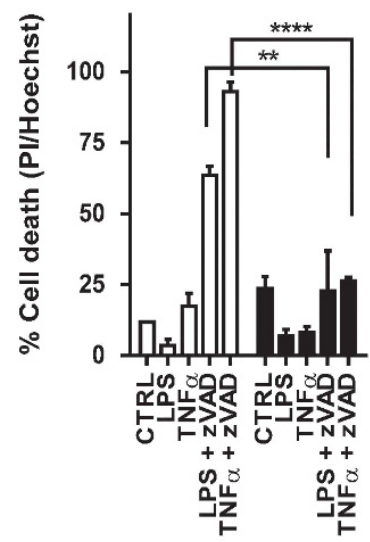

b
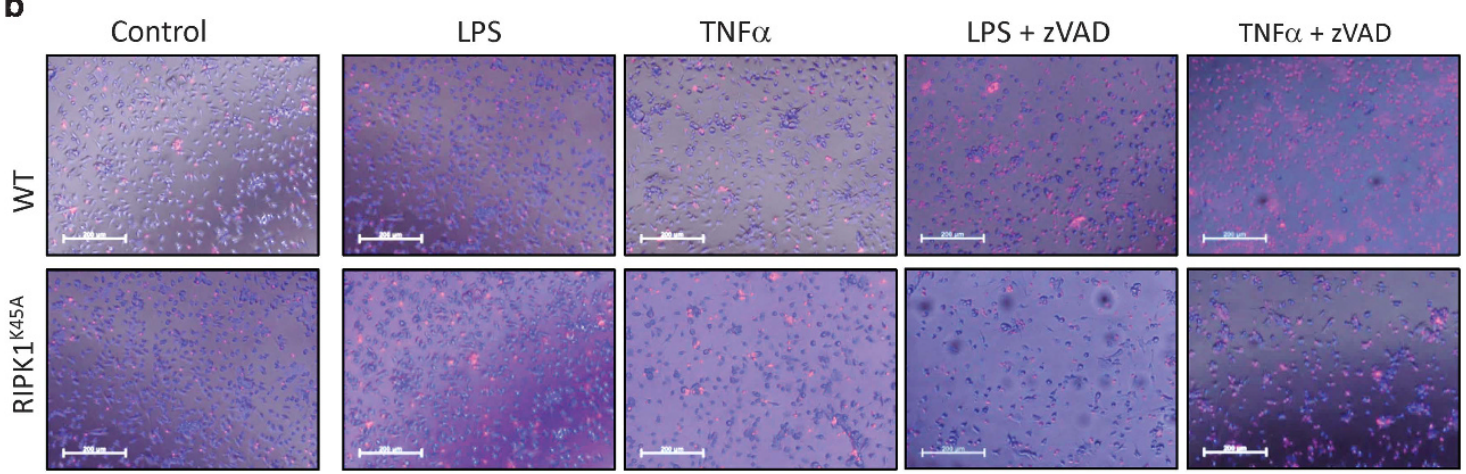

Figure 1 Lysine-45 of RIPK1 promotes necroptosis of macrophages induced by various stimuli. (a) Cell survival of macrophages at $24 \mathrm{~h}$ posttreatment with LPS (100 $\mathrm{ng} / \mathrm{ml}$ ), TNF $\alpha(50 \mathrm{ng} / \mathrm{ml})$, IFN $\beta(100 \mathrm{U} / \mathrm{ml})+1-$ zVAD-fmk $(50 \mu \mathrm{M})$ and/or Nec-1s $(10 \mu \mathrm{M})$, as measured by MTT assay. (b) Images of macrophages treated as in panel (a) and co-stained with propidium iodide (PI) and Hoechst, scale $200 \mu \mathrm{m}$. (c) Numbers of PI-positive cells were quantified as in panel (b). CTRL, non-treated cells. ANOVA with Bonferroni post-test, ${ }^{\star} P<0.05$; ${ }^{* *} P<0.01 ;{ }^{* \star *} P<0.001 ;{ }^{* \star *} P<0.0001$; NS, not significant. Error bars are S.E.M. Graphs show the percentage of surviving cells relative to the cells treated in the absence of zVAD-fmk. Experiments were carried out at least three times

\section{Results}

Lysine-45 of RIPK1 promotes necroptosis of macrophages induced by various stimuli. We have previously shown that lipopolysaccharide (LPS), TNF $a$ and IFN $\beta$ can induce necroptosis of macrophages in the presence of zVAD. ${ }^{14}$ We used a similar approach to evaluate whether the kinase activity of RIPK1 is important in promoting necroptosis of macrophages. Using mice with a mutation in K45 of RIPK $1,{ }^{20}$ our results indicate that RIPK $1^{\mathrm{K} 45 \mathrm{~A}}$ macrophages survive better than the wild-type (WT) macrophages when stimulated with LPS/zVAD, TNFa/zVAD or IFN $\beta /$ ZVAD (Figures 1a-c). For pharmacological inhibition of RIPK1 kinase activity, we also used Nec-1s (the stable variant of necrostatin1 (Nec-1)). ${ }^{21}$ Nec-1s blocked the cell death of WT macrophages when treated with LPS/zVAD, TNFa/zVAD or IFN $\beta / z V A D$ (Figure 1a), indicating that kinase activity of RIPK1 was responsible for the cell death of macrophages. The resistance of $\mathrm{RIPK} 1^{\mathrm{K} 45 \mathrm{~A}}$ macrophages was greatest upon stimulation by TNFa/zVAD in comparison to LPS/zVAD, which is in agreement with previous studies. ${ }^{20,22}$ Furthermore, the resistance of RIPK1 ${ }^{\mathrm{K} 45 \mathrm{~A}}$ macrophages to necroptosis was not as great as that of RIPK3-deficient macrophages (Figure 1a), indicating that there may be additional mechanisms besides the K45 of RIPK1 that promotes cell death.

The kinase activity of RIPK1 promotes trimerization of MLKL. We addressed the mechanisms through which the kinase activity of RIPK1 promotes necroptosis. The phosphorylation of RIPK1 itself was significantly reduced in RIPK1 ${ }^{\mathrm{K} 45 \mathrm{~A}}$ macrophages upon treatment with TNFa/zVAD but not after treatment with LPS/zVAD (Figures $2 a-d$ ). We performed mass spectrometric analysis of immunoprecipitated RIPK1 from BMDMs treated with LPS/ZVAD or TNFa/zVAD for $3 \mathrm{~h}$ in order to identify phosphorylation sites within RIPK1. This analysis showed that Thr-235 and Ser-313 of RIPK1 are phosphorylated in both treatments (Supplementary Figure S1). Furthermore, Thr-235 phosphorylation was significantly attenuated in RIPK1 $1^{\mathrm{K} 45 \mathrm{~A}}$ macrophages following LPS/ZVAD treatment and abolished following TNFa/zVAD treatment. To our knowledge phosphorylation at Thr-235 of RIPK1 has not been reported before. Relative comparison of phosphorylation of Ser-313 was not influenced by K45 of RIPK1 (Supplementary Figure $\mathrm{S} 1 \mathrm{~F})$. However, it is not clear whether the phosphorylation 
a

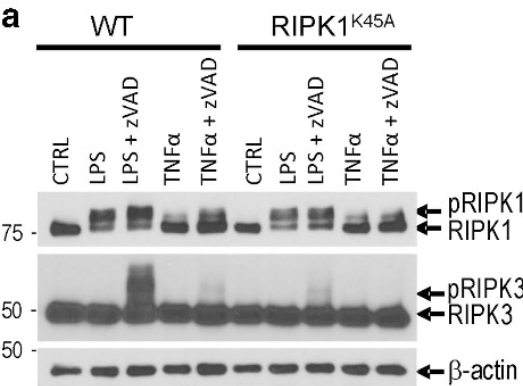

e

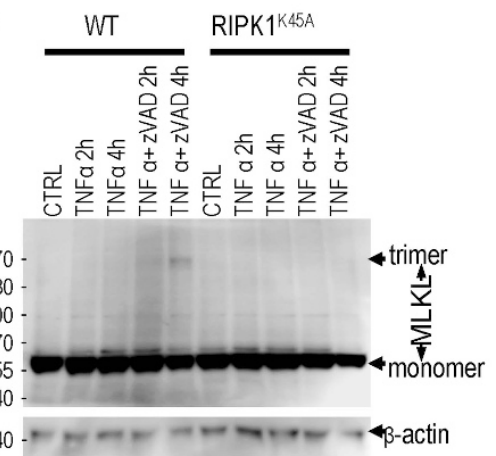

h

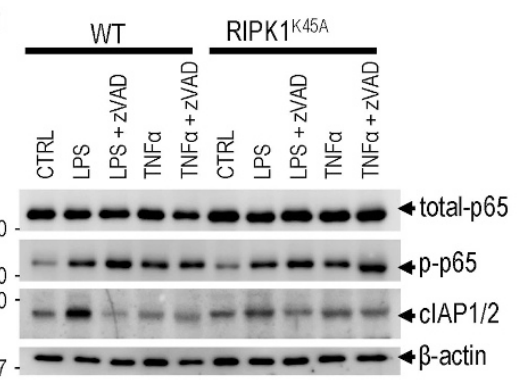

b
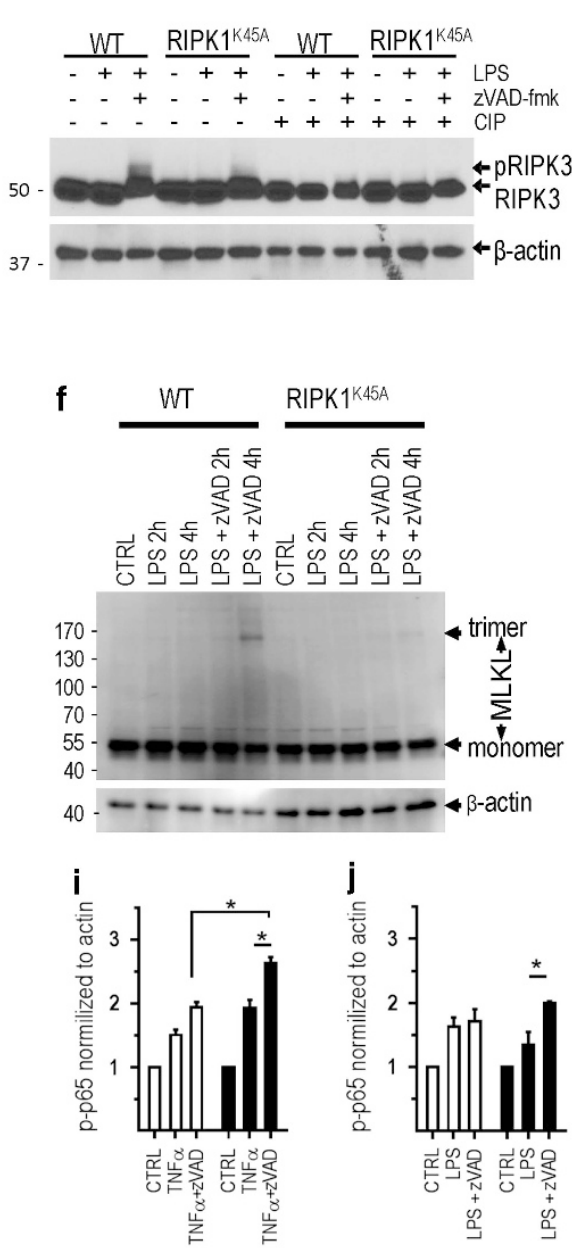

C

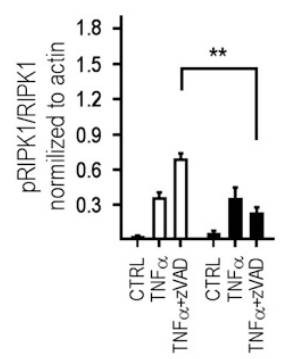

d

g
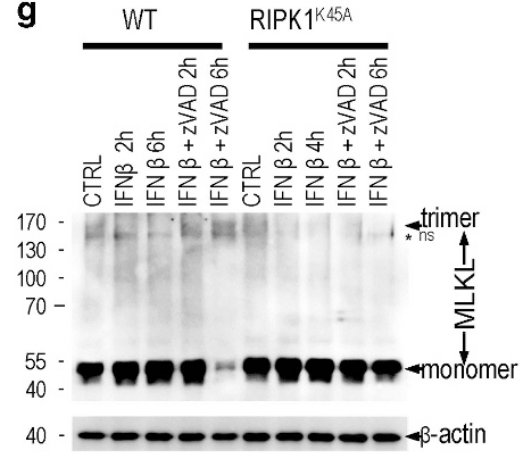

$\mathbf{k}$

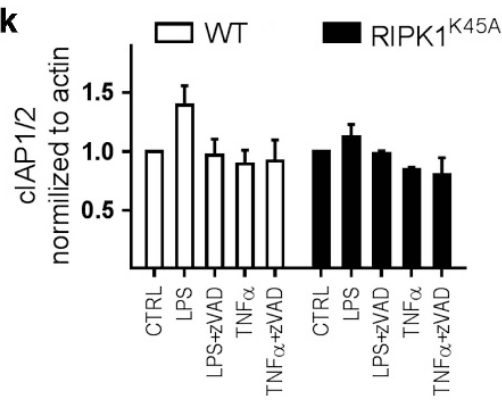

Figure 2 K45 of RIPK1 promotes necroptotic signaling. (a, b, e-h) WTor RIPK1 ${ }^{\mathrm{K} 45 \mathrm{~A}}$ macrophages were treated as indicated in figure panels with LPS (100 ng/ml) and TNF $\alpha$ $(50 \mathrm{ng} / \mathrm{ml})$ with or without zVAD-fmk $(50 \mu \mathrm{M})$, and samples were evaluated by western blotting. Panels (a) and (b) shows western blotting at $3 \mathrm{~h}$ posttreatment. Panel (h) shows western blotting at $4 \mathrm{~h}$ posttreatment. (c, $\mathbf{d}, \mathbf{i}-\mathbf{k})$ Densitometry of pooled western blottings from several experiments. ANOVA with Bonferroni post-test was used to measure statistical significance, ${ }^{*} P<0.05 ;{ }^{* \star} P<0.01$; error bars are S.E.M. Experiments were carried out at least three times

of Thr235 or Ser313 represents a 'necroptosis-specific' modification.

Phosphorylation of RIPK3, a bench mark for necroptosis induction, was also poor in RIPK1 ${ }^{\mathrm{K} 45 \mathrm{~A}}$ macrophages (Figures $2 \mathrm{a}$ and $\mathrm{b}$ ). By dephosphorylating the total proteins from a cell lysate, we show that RIPK3 upper bands are the phosphorylated forms of RIPK3 (Figure 2b). RIPK1 ${ }^{\mathrm{K} 45 \mathrm{~A}}$ macrophages displayed poor trimerization of $M L K L$ in response to TNFa/zVAD (Figure 2e), LPS/zVAD (Figure 2f) or IFN $\beta / z V A D$ (Figure $2 \mathrm{~g}$ ) stimulation. These results clearly demonstrate that the K45 of RIPK1 has a key role in promoting necroptosis of macrophages. Concomitantly, RIPK $1^{\mathrm{K} 45 \mathrm{~A}}$ macrophages displayed slightly increased activation of $N F \kappa \beta$, as assessed by the phosphorylation of p65 upon TNFa/zVAD treatments (Figures $2 \mathrm{~h}$ and $\mathrm{i}$ ). Increased activation of $N F K \beta$ in RIPK1 ${ }^{\mathrm{K} 45 \mathrm{~A}}$ macrophages following TNFR1 ligation is an indication of enhanced cell survival signaling. ${ }^{23}$ In response to LPS/zVAD treatment, phospho-p65 was not modulated by RIPK $1^{\mathrm{K} 45 \mathrm{~A}}$ (Figures $2 \mathrm{~h}$ and $\mathrm{j}$ ). As the cellular inhibitors of apoptosis proteins (clAP1/2) participate in cell signaling following TNF-R engagement, we evaluated whether the levels of clAPs were modulated in RIPK $1^{\mathrm{K} 45 \mathrm{~A}}$ macrophages. Both WT and RIPK1 ${ }^{\mathrm{K} 45 \mathrm{~A}}$ macrophages expressed similar levels of clAPs, which is in line with previous work in MEFs ${ }^{24}$ (Figures $2 \mathrm{~h}$ and $\mathrm{k}$ ).

RIPK1 kinase activity modulates signaling downstream of TNF-R. As TNFa signaling following receptor engagement involves activation (phosphorylation) of STAT1, ${ }^{25-27}$ we measured pS727-STAT1 levels following LPS/ZVAD or TNFa/zVAD treatment of macrophages. Phosphorylation of STAT1 was reduced in RIPK1 ${ }^{\mathrm{K} 45 \mathrm{~A}}$ macrophages following LPS/zVAD treatment (Figures $3 a$ and $b$ ). More interestingly, pS727-STAT1 levels after TNFa/zVAD were blunted in RIPK1 ${ }^{\mathrm{K} 45 \mathrm{~A}}$ macrophages (Figures $3 c$ and $d$ ) even as early as $1 \mathrm{~h}$ poststimulation. This differential phosphorylation of S727-STAT1 between WT and RIPK $1^{\text {K45A }}$ macrophages is not observed during non-necroptotic stimulations (Supplementary 


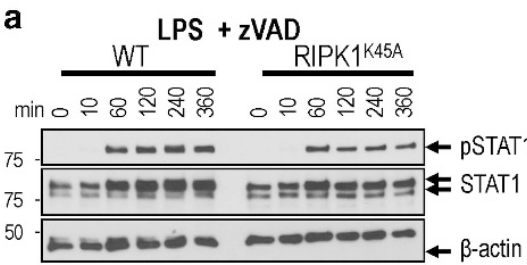

C
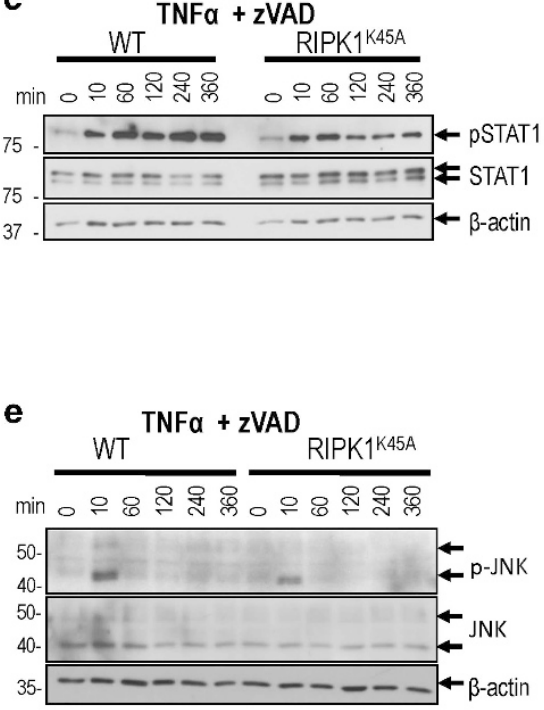

b

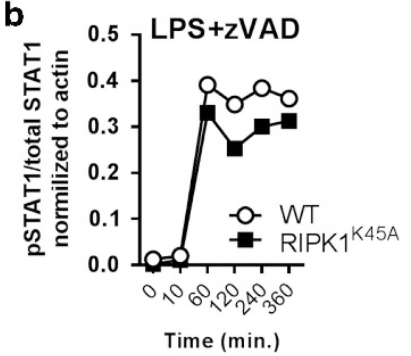

d

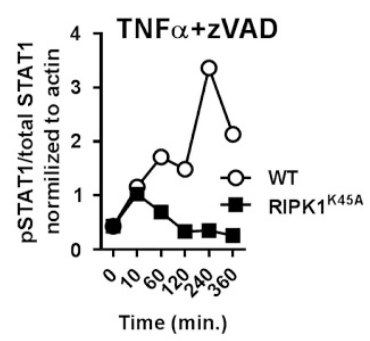

f

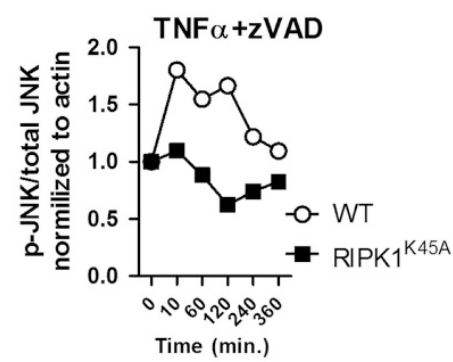

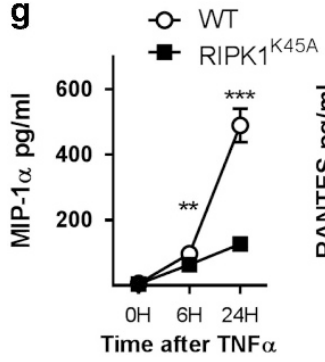
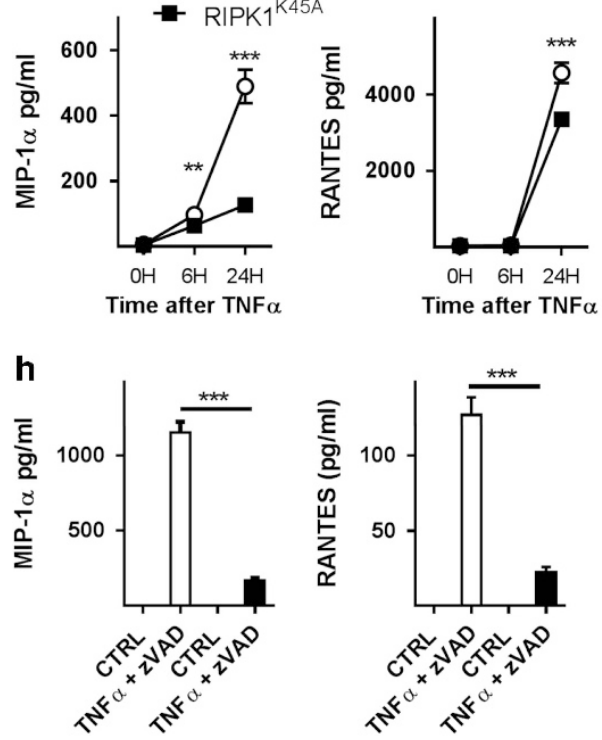

i

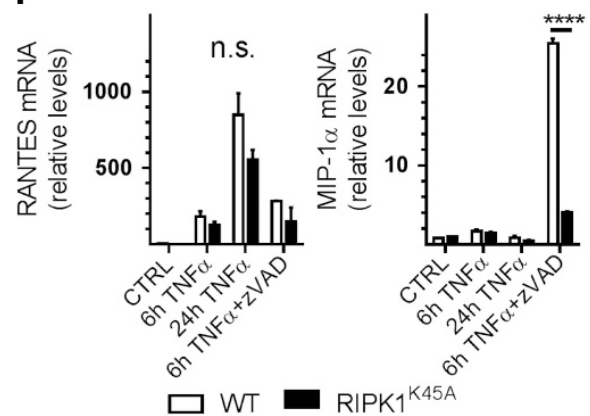

Figure 3 RIPK1 ${ }^{\mathrm{K} 45 \mathrm{~A}}$ impacts JNK activation, STAT1 phosphorylation at position S727 and chemokine production by macrophages. WT or RIPK1 ${ }^{\mathrm{K} 45 \mathrm{~A}}$ macrophages were treated as indicated in the panels and tested for STAT1 and JNK phosphorylation $(\mathbf{a}, \mathbf{c}, \mathbf{e})$ by western blotting analysis. (b, $\mathbf{d}$, f) Densitometric analysis of the representative western blottings. Chemokine production by macrophages was measured $(\mathbf{g})$ at various time intervals or $(\mathbf{h})$ at $6 \mathrm{~h}$ poststimulation of cells. (i) mRNA levels of the chemokines measured in panels ( $\mathbf{g}$ and $\mathbf{h}$ ) were analyzed under same conditions. The mRNA levels were normalized to rpp30. ANOVA with Bonferroni post-test was used to measure statistical significance, ${ }^{* \star} P<0.01 ;{ }^{* * *} P<0.001 ;{ }^{* * *} P<0.0001$; NS, not significant; error bars are S.E.M. Experiments carried out at least three times

Figures S2A and B; treatment with LPS or TNFa in the absence of ZVAD).

Furthermore, TNF-R signaling also initiates a rapid and transient induction of C-Jun N-terminal kinase (JNK). ${ }^{28}$ In this regard, TNFa/zVAD treatment of RIPK1 ${ }^{\mathrm{K} 45 \mathrm{~A}}$ macrophages resulted in diminished levels of $p$-JNK (Figures $3 e$ and $f$ ). These results pinpoint to a mechanism wherein the phosphorylation by RIPK1 impacts TNFa signaling. Thus we measured cytokine or chemokine production following treatment of macrophages with TNFa or TNFa/zVAD. The levels of chemokines MIP-1 $a$ and RANTES were significantly induced in WT macrophages following stimulation of cells with TNFa alone (Figure $3 \mathrm{~g}$ ) or TNFa/zVAD (Figure $3 \mathrm{~h}$ ) for $6 \mathrm{~h}$. In contrast, RIPK1 ${ }^{\mathrm{K} 45 \mathrm{~A}}$ macrophages showed reduced expression of these chemokines. In addition to this, low mRNA levels of MIP-1a after TNFa/zVAD stimulation are indicative of a RIPK1-dependent transcriptional regulation of MIP-1a (Figure $3 \mathrm{i})$. When these BMDMs were treated with LPS/zVAD for $6 \mathrm{~h}$, the expression of IL-1a, TNF $a$ and IL-10, but not IL-6, were reduced in RIPK1 ${ }^{\mathrm{K} 45 \mathrm{~A}}$ macrophages (Supplementary Figure S2C).

In the absence of PAMPs, K45 of RIPK1 is necessary for auto-phosphorylation of RIPK1, which is inhibited by cIAPs. Treatment with a mimetic of the second mitochondrial activator of apoptosis (SMAC) induces regulated cell death of macrophages even in the absence of any PAMP stimulation, and this is induced by rapid degradation of ClAPs by SMAC. ${ }^{29}$ Stimulation of macrophages with the SMAC mimetic, birinapant $(\mathrm{BP})$ resulted in a significant loss of cell viability, which was further enhanced by co-treatment with zVAD, and was rescued by treatment with Nec-1 (Figure 4a). Interestingly, RIPK1 ${ }^{\mathrm{K} 45 \mathrm{~A}}$ macrophages displayed potent resistance to cell death in this model (Figure 4a). Similar results were noted when cells were stained with $\mathrm{Pl} /$ Hoechst (Figure 4c and Supplementary Figure S3A), suggesting that the kinase activity RIPK1 has an even greater role in PAMP-independent necroptosis. The cell death of WT 


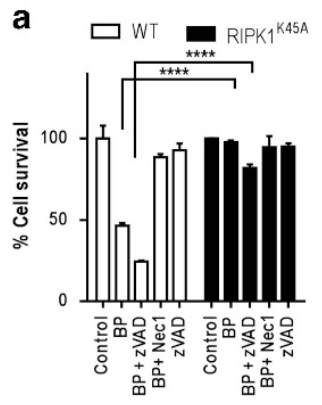

b

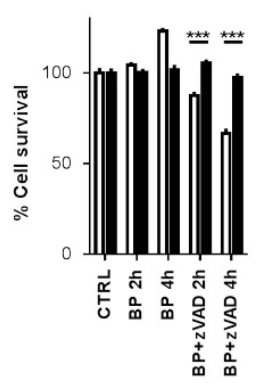

c

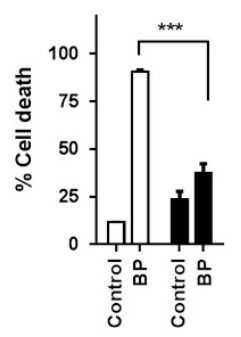

d

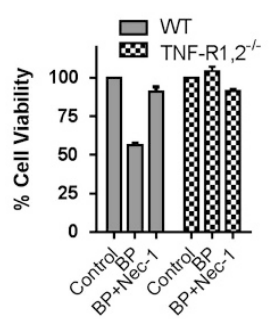

e
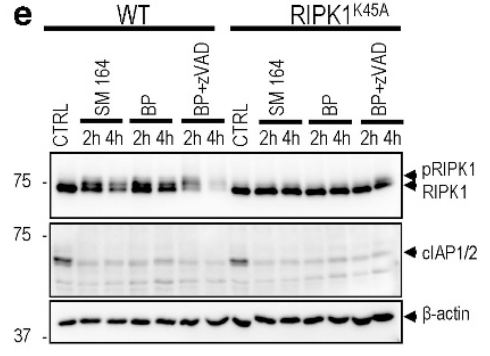

f

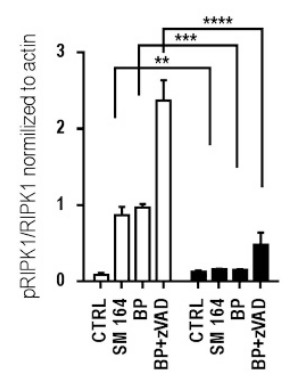

g

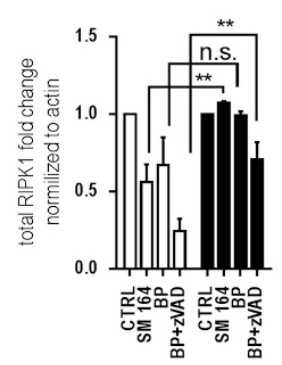

h

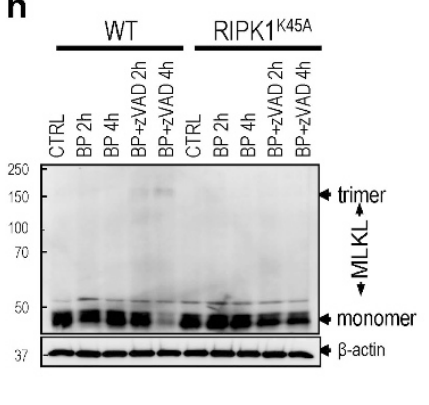

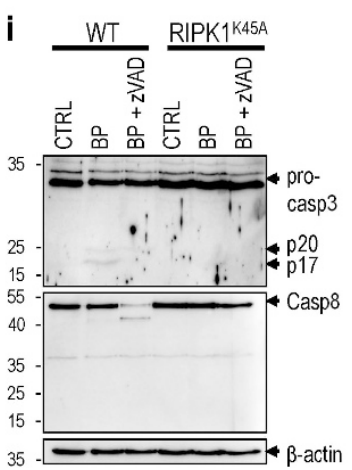

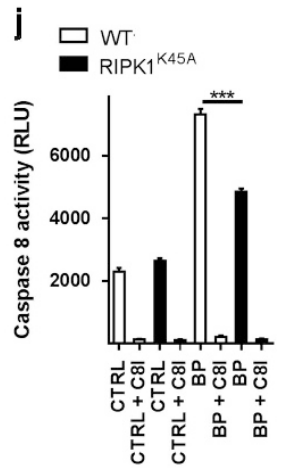

Figure 4 Lysine-45 of RIPK1 is necessary for RIPK1 auto-phosphorylation following depletion of clAPs. Cell survival of macrophages was measured by MTT assay after (a) $24 \mathrm{~h}$ and (b) 2 or $4 \mathrm{~h}$ posttreatment of cells with SMAC mimetic (BP, $10 \mu \mathrm{M}$ ) with or without zVAD-fmk (50 $\mu \mathrm{M})$ or Nec-1 (10 $\mu \mathrm{M})$. Graphs show the percentage of surviving cells relative to the corresponding vehicle control. These graphs are representative of three biological replicates each carried out in triplicate. (c) Cell death of macrophages after $24 \mathrm{~h}$ treatment with BP as measured microscopically by PI/Hoechst staining. (d) WTor TNF-R1, $2^{-1}$ macrophages were treated as in panel (a) and assessed for survival by MTT assay. (e, h, i) WTor RIPK1 ${ }^{445 A}$ macrophages were prepared for western blotting at the indicated times $(\mathbf{i}-4 \mathrm{~h})$ posttreatment with BP $(10 \mu \mathrm{M})$ with or without zVAD-fmk $(50 \mu \mathrm{M})$ or SMAC $164(5 \mu \mathrm{M})$. (f, $\mathbf{g})$ Densitometry data of pooled three western blotting experiments as in panel (e) at 4-h treatment was used to assess p-RIPK1/RIPK1 ratio (f) or total RIPK1 levels (g). (j) Caspase 8 activity was measured with the Luciferase Kit from Promega at $4 \mathrm{~h}$ posttreatment; C8I, caspase 8 inhibitor. ANOVA with Bonferroni post-test was used to measure statistical significance, ${ }^{* \star} P<0.01 ;{ }^{* * *} P<0.001 ;{ }^{* * \star} P<0.0001$; error bars are S.E.M. NS, not significant. Experiments were repeated at least three times

macrophages upon treatment with BP and ZVAD was detectable as early as $2 \mathrm{~h}$ posttreatment (Figure $4 \mathrm{~b}$ ), while $\mathrm{BP}$ alone failed to cause cell death at that time point. BP induced cell death was dependent on TNF-R signaling (Figure 4d). Treatment of cells with the SMAC mimetic (SM164 or BP) resulted in rapid degradation of clAPs as expected, but the phosphorylation of RIPK1 was totally abrogated in RIPK $1^{\mathrm{K} 45 \mathrm{~A}}$ macrophages (Figures $4 \mathrm{e}$ and $\mathrm{f}$ ). Treatment of WT macrophages with SMAC mimetics resulted in a significant reduction of RIPK1 levels, which was significantly inhibited in $\mathrm{RIPK} 1^{\mathrm{K} 45 \mathrm{~A}}$ macrophages (Figure $4 \mathrm{~g}$ ). Furthermore, trimerization of MLKL was also abrogated in RIPK $1^{\mathrm{K} 45 \mathrm{~A}}$ macrophages treated with SMAC $+z V A D$ (Figure $4 \mathrm{~h}$ ). We then tested whether the death of macrophages induced by SMAC mimetic results in the activation of caspase 3 and caspase 8 . The cleaved forms of caspase 3 ( $\mathrm{p} 17$ and p20) were detectable by western blotting in SMAC mimetic-treated WT macrophages but not in RIPK $1^{\mathrm{K} 45 \mathrm{~A}}$ macrophages (Figure 4i). Although the cleaved form (p18) of caspase 8 was undetectable by western blotting (Figure 4i), caspase 8 activity was readily detectable in a luminescence assay, which was inhibited by caspase 8-specific inhibitor (Figure 4j) or by $\mathrm{N}$-benzyloxycarbonylVal-Ala-Asp(O-Me) fluoromethyl ketone (zVAD-fmk; Supplementary Figure S3B). Treatment of macrophages with the
SMAC mimetic resulted in significant induction of caspase 8 activity relative to control in both genotypes. However, caspase 8 activity was induced stronger in WT than in the RIPK1 ${ }^{\mathrm{K} 45 \mathrm{~A}}$ macrophages (Figure $4 \mathrm{j}$, Supplementary Figure S3B). In the absence of zVAD treatment, SMAC mimetic induced the activation of caspase 3 , caspase 8 and cell death of WT but not in RIPK $1^{\mathrm{K} 45 \mathrm{~A}}$ macrophages.

RIPK1 ${ }^{\mathrm{K} 45 \mathrm{~A}}$ mice display enhanced survival against endotoxin shock and poor control of Salmonella typhimurium (ST) in vivo. $\mathrm{RIPK} 1^{\mathrm{K} 45 \mathrm{~A}}$ mice displayed enhanced survival following endotoxin shock in comparison to WT controls (Figures $5 a$ and $b$ ). IL-1 $\beta$ and TNF $\alpha$ levels in the sera of endotoxin-injected mice were lower in RIPK $1^{\mathrm{K} 45 \mathrm{~A}}$ mice (Figure 5c), and the lower level of TNFa may be responsible for decreased expression of MIP-1a (Supplementary Fig. S4). Dysregulation in cytokine response was also detected in macrophages stimulated in vitro with LPS (Figure $5 d$ ), which correlated with reduction in the mRNA levels of IL- $1 \beta$ and TNF $\alpha$ (Figure 5e). These results prompted us to test the impact of $\mathrm{K} 45 \mathrm{~A}$ mutation during challenge with a virulent intracellular bacterium. We challenged mice with low dose of ST and measured the bacterial burden in the spleens of infected mice at day 5 postintravenous infection. Our results show that RIPK1 ${ }^{\mathrm{K} 45 \mathrm{~A}}$ mice harbor higher burden of ST 
a

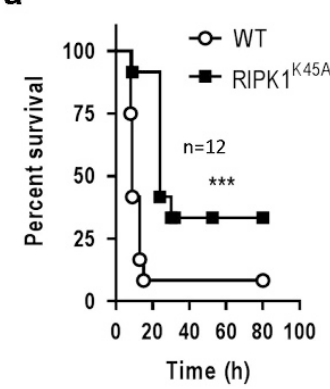

b

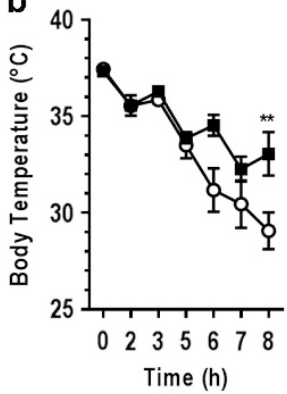

c

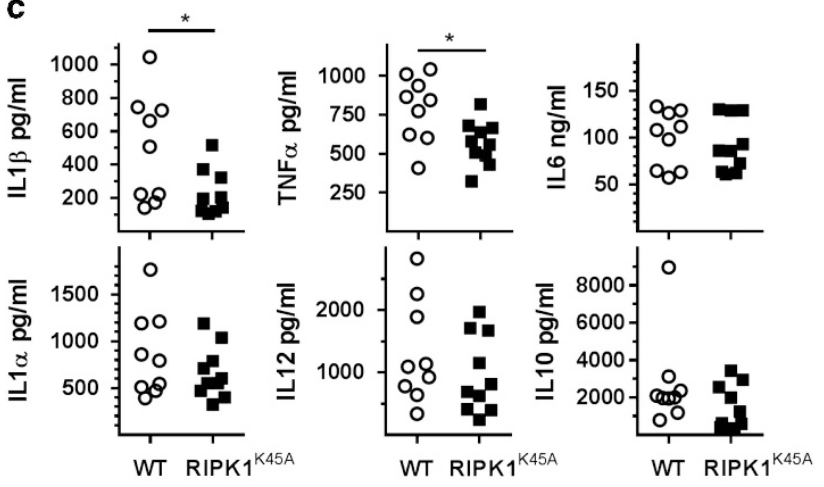

d
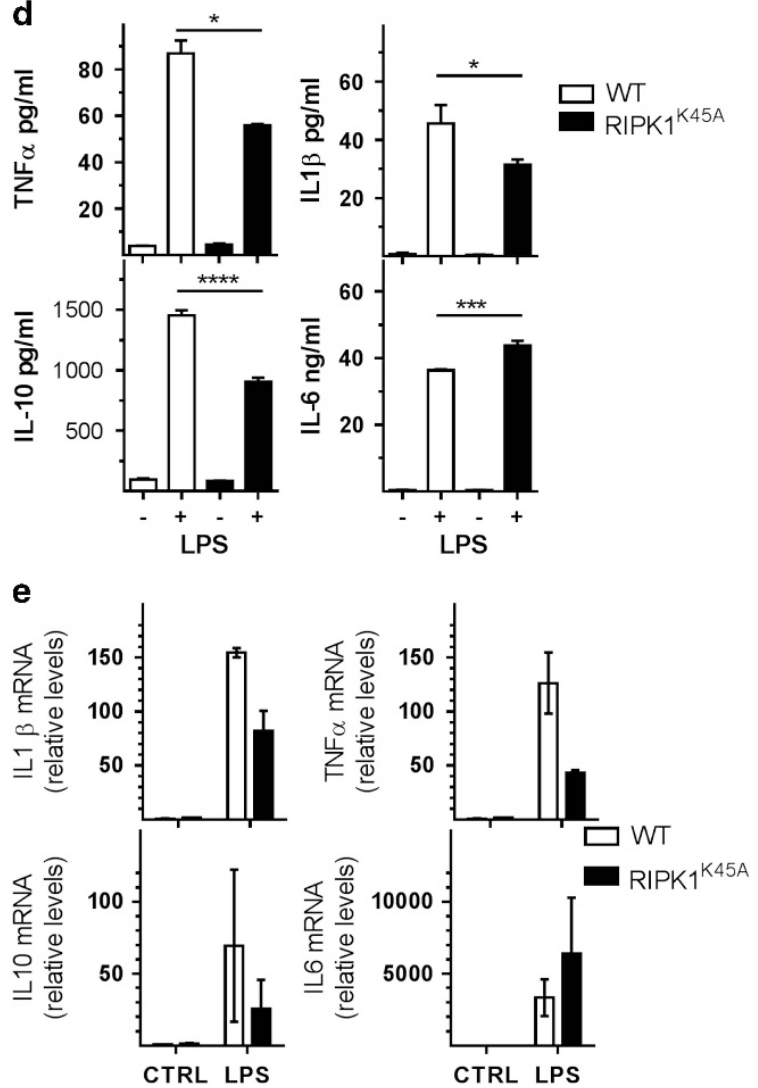

Figure 5 The kinase activity of RIPK1 promotes susceptibility to endotoxic shock. (a) Enhanced survival of RIPK1 ${ }^{\mathrm{K} 45 \mathrm{~A}}$ mice after intraperitoneal injection with LPS (50 mg/ $\mathrm{kg}$ ). Graph represents pooled data of three separate experiments. Mantel-Cox test was used to evaluate the statistical significance. (b) RIPK $1^{\mathrm{K} 45 \mathrm{~A}}$ mice maintain higher body temperature than the WT mice following LPS injection as described in panel (a). ANOVA was used to evaluate statistical significance. (c) Cytokine levels in sera of WT or RIPK1 ${ }^{\mathrm{K} 45 \mathrm{~A}}$ mice after $5 \mathrm{~h}$ of intraperitoneal (i.p.) injection with LPS $(50 \mathrm{mg} / \mathrm{kg}$ ). Graphs are pooled data of three separate experiments. Statistical significance was measured by t-test. (d) Cytokine production by macrophages at $24 \mathrm{~h}$ poststimulation (in vitro) by LPS (100 ng/ml). (e) mRNA levels of cytokines in macrophages at $6 \mathrm{~h}$ posttreatment (normalized to rpp30). ${ }^{*} P<0.05 ;{ }^{* *} P<0.01 ;{ }^{* * *} P<0.001 ;{ }^{* * * *} P<0.0001$, error bars are S.E.M.

(Figure 6a and Supplementary Figures S5A and B) that is associated with increased splenomegaly (Figure 6b). The numbers of spleen cells were also increased in infected RIPK1 ${ }^{\mathrm{K} 45 \mathrm{~A}}$ mice (Figure 6c). RIPK1 ${ }^{\mathrm{K} 45 \mathrm{~A}}$ macrophages displayed reduced level of reactive oxygen species (ROS) following ST infection in vitro, as measured by DCF staining (Figure 6d) and reduced release of glucose-6-phosphate dehydrogenase (G6PD), indicative of reduced cell death (Figure 6e). RIPK $1^{\mathrm{K} 45 \mathrm{~A}}$ macrophages infected with ST in vitro expressed reduced IL-1 $\beta$ in comparison to WT macrophages (Figure 6f). Upon infection with ST, caspase 8 activity was reduced, and this reduction was even more pronounced in RIPK $1^{\mathrm{K} 45 \mathrm{~A}}$ macrophages (Figure $6 \mathrm{~g}$ ). Taken together, our results reveal the impact of the kinase domain of RIPK1 on necroptosis and cytokine signaling during inflammatory (PAMPs, cytokines) and non-inflammatory stimuli (SMAC).

\section{Discussion}

RIPK1 interacts with various proteins such as clAPs and TRAFs that are associated with the TNF-R. ${ }^{9}$ Dissociation of RIPK1 from this complex results in interaction of RIPK1 with caspase 8, FADD and RIPK3, which promotes cell death signaling by apoptosis or necrosis. ${ }^{9}$ RIPK1-deficient mice die within the first week of birth ${ }^{5}$ as a result of uncontrolled activation of necrosis and apoptosis mediated by RIPK3 and caspase $8,{ }^{6,30}$ suggesting that RIPK1, RIPK3 and caspase 8 regulate the overactivation of each other. As RIPK3-deficient mice are viable, ${ }^{31}$ this suggests that RIPK1 has additional roles besides necroptosis. We have evaluated the role of the kinase region of RIPK1 in macrophages and its consequent impact in vivo. Our results indicate that RIPK1 kinase-dead $\left(\mathrm{RIPK} 1^{\mathrm{K} 45 \mathrm{~A}}\right.$ ) mice do not have any impairment in survival; however, they are highly resistant to necroptosis induced by various stimuli, and they display reduced TNF-R signaling, caspase 8 activation and IL- $1 \beta$ expression, which results in significant protection against endotoxin shock and compromised control of an infection with a virulent intracellular bacterium.

Our results indicate that RIPK $1^{\mathrm{K} 45 \mathrm{~A}}$ macrophages are significantly, but not completely, resistant to necroptotic stimulation by LPS. In contrast, RIPK $1^{\mathrm{K} 45 \mathrm{~A}}$ macrophages displayed a greater resistance to necroptosis upon stimulation by TNF $a$ or IFN $\beta$. As both RIPK1 and RIPK3 can promote necroptosis as well apoptosis, ${ }^{22,32,33}$ reduced oligomerization of MLKL is indicative of reduced necroptosis in RIPK $1^{\mathrm{K} 45 \mathrm{~A}}$ 


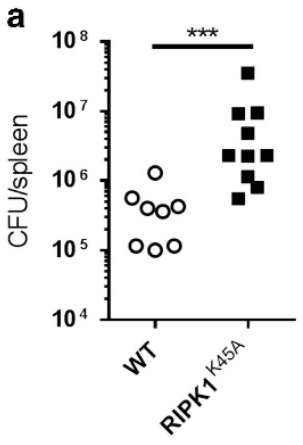

b

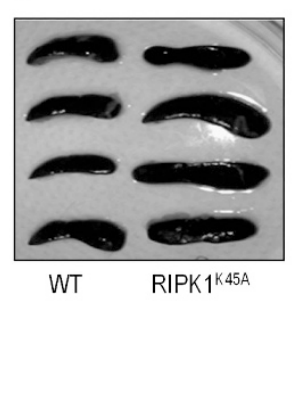

C

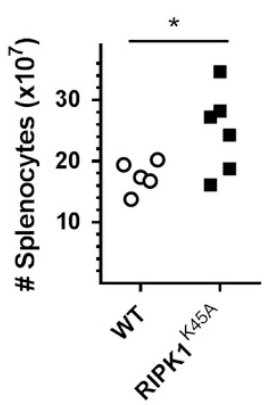

d

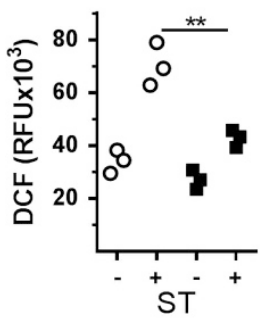

e

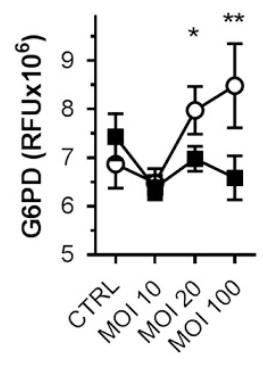

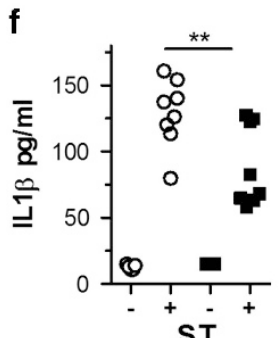

ST
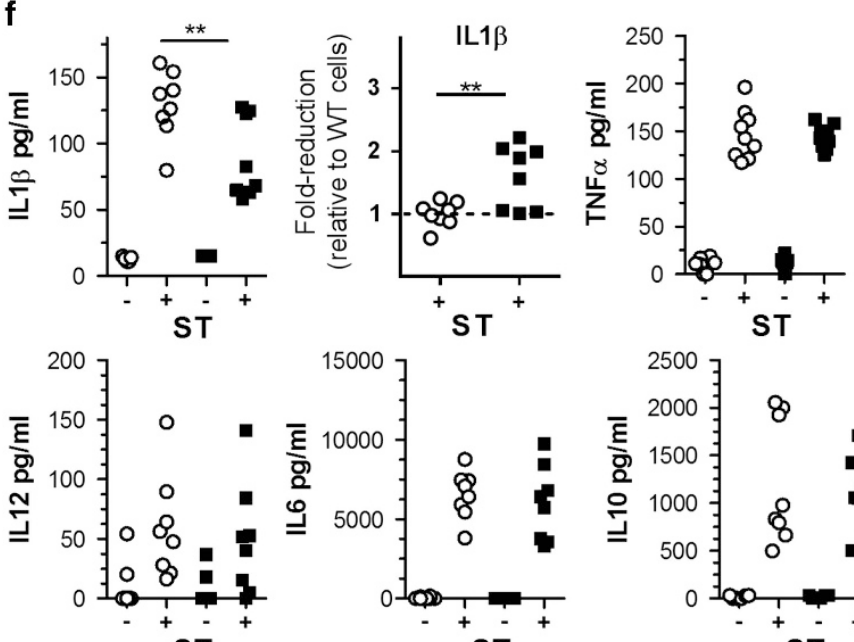

ST
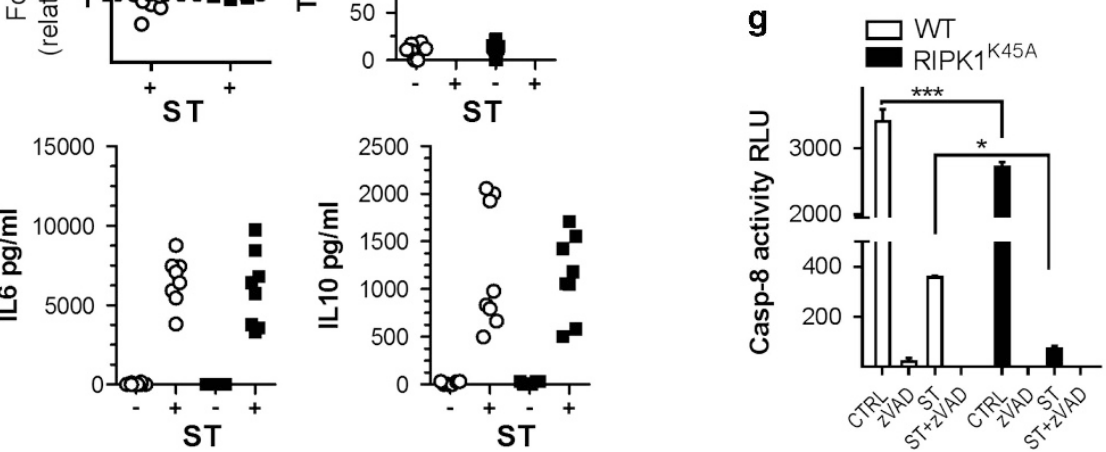

Figure 6 Kinase activity of RIPK1 promotes inflammatory response against ST. (a) ST burden in the spleen of WTor RIPK1 ${ }^{\mathrm{K} 45 \mathrm{~A}}$ mice was evaluated at day 5 postintravenous injection of 200 bacteria. Graph represents pooled data of three separate experiments. Mann-Whitney test was used to measure statistical significance, (b) image of the spleens at day 5 postinfection, (c) number of total splenocytes after infection as in panel (a). (d) ROS levels were measured at $24 \mathrm{~h}$ postinfection of macrophages with ST (10 MOI) in vitro. (e) Glucose 6-phosphate dehydrogenase (G6PD) release after ST infection at $24 \mathrm{~h}$ postinfection. The plot shown is representative of two biological repeats. (f) Cytokine levels were measured by ELISA at $24 \mathrm{~h}$ postinfection (in vitro) of macrophages with ST. Data are pooled from three separate experiments, all carried out in triplicate. The IL-1 $\beta$ cytokine levels from panel (f) were also represented as fold-reduction relative to arithmetic mean of the cytokine levels in WT cells. Line at 1 is the arithmetic mean of WT cell cytokine levels. (g) Caspase 8 activity after ST infection at $3 \mathrm{~h}$ postinfection, measured using a Luciferase Kit from Promega. The plot shown is representative of two biological repeats. ${ }^{\star} P<0.05 ;{ }^{* \star} P<0.01 ;{ }^{* * *} P<0.001$, error bars are S.E.M. RFU, relative fluorescence unit

macrophages because oligomerization of MLKL has been considered to be mainly associated with necroptosis. ${ }^{34}$ We show that MLKL trimer formation is dependent on the RIPK1 kinase activity in all necroptotic stimuli. Here again, we noted differences in the extent of inhibition of signaling in RIPK $1^{\mathrm{K} 45 \mathrm{~A}}$ macrophages that was dependent on the stimulus used. There was total inhibition of MLKL oligomerization following treatment with SMAC/zVAD or TNFa/zVAD in comparison to stimulation with LPS/ZVAD where MLKL oligomerization was reduced. This also correlated well with the extent of cell death. Interestingly, K45-dependent auto-phosphorylation of RIPK1 appears to be the main mechanism of RIPK1 phosphorylation when macrophages are treated with SMAC or TNFa/zVAD. However, when cells were treated with LPS, RIPK1 phosphorylation did not appear to be impacted by K45 of RIPK1. This is in line with the notion that engagement of TLR4 may lead to multiple and redundant activation of signaling proteins, ${ }^{35}$ notably the TAK1 (TGF $\beta$-activated kinase 1). Activated TAK1 can activate RIPK3-MLKL axis independently of RIPK1 leading to regulated necrotic cell death. ${ }^{36}$
Interestingly, Nec-1s treatment results in a slight but significant enhancement of survival of RIPK $1^{\mathrm{K} 45 \mathrm{~A}}$ macrophages following LPS, TNF $\alpha$ or IFN $\beta$ treatment (Figure 1a). As $\mathrm{Nec}-1 \mathrm{~s}$, in contrast to $\mathrm{Nec}-1$, specifically inhibits the kinase activity of RIPK $1,{ }^{21}$ these results suggest that Nec-1s may inactivate other regions of RIPK1, which may impact necroptosis further.

When macrophages were treated with TNFa/zVAD, the kinase activity of RIPK1 seemed to inhibit the activation of $N F \kappa \beta$. Although RIPK1 was shown to previously promote $N F \kappa \beta$ activation ${ }^{5,37}$ in MEFs, our results indicate that the kinase activity (K45) of RIPK1 may negatively regulate $N F k \beta$ signaling in macrophages. It is not clear whether these differences are related to the cell type. As RIPK1 participates in various signaling complexes following TNF-R engagement, it is conceivable that the transitioning of RIPK1 between TNF-R1 complex I and complex $2 \mathrm{~b}$ may be delayed in RIPK1 ${ }^{\mathrm{K} 45 \mathrm{~A}}$ macrophages, leading to enhanced signaling through complex I for $\mathrm{NF} \kappa \beta$. 
Interestingly, the K45A mutation of RIPK1 significantly impacted cytokine signaling as revealed by poor p-STAT1 phosphorylation at $\mathrm{S} 727$ during necroptotic stimulation, which in turn may reflect the reduction in caspase activity. Phosphorylation of STAT1 at Y701 is required to decouple the STAT1 from TNF-R, ${ }^{26}$ but phosphorylation at $S 727$ is required for maximal STAT1-dependent gene transcription. ${ }^{25}$ Our results indicate an impairment in chemokine expression in RIPK1 kinase-dead macrophages, which correlated with S727-STAT1 phosphorylation. Signaling through the TNF-R and IFNA-R is mediated through STAT1 phosphorylation. ${ }^{38}$ However, the phosphorylation of STAT1 is blunted early on (1 $\mathrm{h}$ upon stimulation) in RIPK $1^{\mathrm{K} 45 \mathrm{~A}}$ macrophages pointing to an early impairment in phosphorylation most likely localized at the TNF-receptor complex. We also noted that the kinase activity of RIPK1 promotes rapid induction of JNK following TNFa/zVAD treatment. JNK has been shown to promote ROS production, ${ }^{39}$ and reduction in ROS levels may impact necroptosis. ${ }^{2}$ These results suggest that K45 of RIPK1 has a key role in promoting chemokine signaling, which is indicative of a mechanism through which RIPK1 promotes inflammatory response.

We also noted that, in the absence of clAPs, the stability of RIPK1 is dependent on the kinase activity (K45) of RIPK1. It is therefore likely that the kinase activity of RIPK1 inhibits signaling that promotes RIPK1 degradation. It is also possible that the lysine- 45 of RIPK1 is itself the target for ubiquitination leading to degradation, hence a mutation of this amino acid impacts RIPK1 stability. Furthermore, the cell survival after clAP depletion is dependent on RIPK1 kinase activity and requires TNF-R signaling, similarly to previous reports. ${ }^{40}$

Recently, in a mouse model of inflammation in the skin that is induced by SHARPIN-deficiency, RIPK1 kinase-dead mice displayed significant rescue ${ }^{20}$ whereas in the models of gut inflammation the kinase activity of RIPK1 did not promote severe colitis. ${ }^{24,41}$ Further, it was shown that RIPK1 and RIPK3 are found in a complex with caspase 8 and caspase 1 where the kinase activity of RIPK1 is dispensable. ${ }^{42,43}$ However, in vivo deficiency of RIPK1 kinase activity is shown to be deleterious for the host after Vaccinia virus infection. ${ }^{40}$ Our results highlight the impact of the kinase domain of RIPK1 in two models of inflammation. RIPK $1^{\mathrm{K} 45 \mathrm{~A}}$ mice display enhanced survival against endotoxin shock, yet they are highly susceptibility to a challenge with ST. Enhanced survival of RIPK $1^{\mathrm{K} 45 \mathrm{~A}}$ mice following endotoxin shock is not as strong as seen in mice with disrupted inflammasome signaling, ${ }^{44-46}$ suggesting that RIPK $1^{\mathrm{K} 45 \mathrm{~A}}$ may not modulate the dominant pathway of inflammasome signaling, which is mediated by caspase $11 .{ }^{47}$ However, the impact of RIPK $1^{\mathrm{K} 45 \mathrm{~A}}$ mice on the control of ST appears to be similar to what has been published in inflammasome-deficient mice. ${ }^{48}$ These results indicate that the impact of the kinase activity of RIPK1 in promoting inflammation is dependent on the experimental model. Interestingly, in macrophages, our in vitro results also point to a transcriptional regulation of cytokine activation that is dependent on RIPK1 kinase activity. Although the kinase activity promotes the production of IL-1 $\beta$, TNF $\alpha$ and IL-10, it impedes IL6 production, similarly to a previous report on IL6 production in MEFs. ${ }^{37}$ Intriguingly, we noted reduced levels of only IL- $1 \beta$ and TNF $\alpha$ in RIPK $1^{\mathrm{K} 45 \mathrm{~A}}$ mice.
RIPK $1^{\mathrm{K} 45 \mathrm{~A}}$ mice were highly susceptible to infection by ST, which correlated with reduced expression of IL-1 $\beta, \mathrm{ROS}$ and reduced cell death of RIPK $1^{\mathrm{K} 45 \mathrm{~A}}$ macrophages. The 16-fold enhanced burden of ST in RIPK $1^{\mathrm{K} 45 \mathrm{~A}}$ mice is similar in magnitude to what has been shown previously in mice lacking inflammasome signaling. ${ }^{48}$ Although the processing of the IL-1 cytokine family has been shown to promote protection against pathogens, ${ }^{48}$ cell death has also been to limit pathogen spread through release of intracellular bacteria for uptake and killing by neutrophils, independently of IL-1. ${ }^{49}$ Although caspase $1 / 11$ signaling promotes canonical inflammasome signaling, caspase 8 and other members of the ripoptosome complex have also been shown to promote inflammasome activation. ${ }^{50-54}$ Our results show that caspase 8 activity was reduced in $\mathrm{RIPK} 1^{\mathrm{K} 45 \mathrm{~A}}$ macrophages, which may limit IL-1 $\beta$ processing in RIPK $1^{\mathrm{K} 45 \mathrm{~A}}$ macrophages. We observed that the activity of caspase 8 was reduced in macrophages following infection with ST. Interestingly, caspase 1 , which is activated during infection with ST, has been previously shown to limit the processing of various caspases. ${ }^{55}$

Although the molecular mechanisms that govern the inflammasome and necrosome activation are quite distinct, the end result in both cases is membrane rupture and release of damage-associated molecular patterns, leading to excessive inflammation. ${ }^{9,56}$ Although RIPK3 is a key component of the necrosome complex, and we have previously shown that RIPK3 is activated following ST infection, ${ }^{57}$ RIPK3 has also been shown to promote inflammasome signaling. ${ }^{11,50,51,53}$ More recently, MLKL, another member of the necrosome, has also been shown to promote inflammasome signaling, ${ }^{58}$ indicating that there is significant overlap in inflammasome and necrosome signaling. We have previously shown that WT and RipK3 ${ }^{-1-}$ mice harbor similar bacterial burden at day 5 postinfection with $\mathrm{ST}^{57}$ whereas, in our current study, the bacterial burden in RIPK $1^{\mathrm{K} 45 \mathrm{~A}}$ is much higher than in WT mice (Figure 6a). It is quite likely that this is related to the participation of RIPK1 in additional signaling platforms such as the Ripoptosome and the impact of RIPK1 that we have shown on TNFa signaling. Our results indicate that the kinase activity of RIPK1 promotes inflammatory cell death and processing of various inflammatory cytokines. Expression of inflammatory cytokines is akin to a double-edged sword wherein the expression of these cytokines promotes protection against pathogens but promotes lethality during sterile injury. Impairment in the processing and expression of various inflammatory cytokines by RIPK $1^{\mathrm{K} 45 \mathrm{~A}}$ macrophages would result in poor control of virulent pathogens such as ST but better protection against endotoxin shock. It is also conceivable that RIPK $1^{\mathrm{K} 45 \mathrm{~A}}$ mice show better protection in other models of sterile inflammation. Delineation of the mechanisms through which the kinase region of RIPK1 influences host outcome would lead to the development of therapeutics against inflammatory diseases.

\section{Materials and Methods}

Mice. RIPK1 $1^{\mathrm{K} 45 \mathrm{~A}}$ mice ${ }^{20}$ and WT litter mates were maintained in our animal facility. RIPK3 ${ }^{-1-}$ were a kind gift from Dr Vishva Dixit (Genentech, San Francisco, CA, USA). ${ }^{31}$ TNF-R1, $2^{-1-}$ mice were purchased from the Jackson Laboratory (Bar Harbor, ME, USA). Experiments were performed in accordance with the Canadian 
Council on Animal Care guidelines and the Ethics Board and/or the Animal Care Committee at the University of Ottawa, Ottawa, ON, Canada.

In vivo endotoxin shock model. Mice (litter mates only) were age and sex matched, their weight was measured and the average mass of all mice per experiment was used for calculating the concentration of intraperitoneally injected LPS (50 mg/kg) (LPS from Escherichia coli 055:B5, L4005, Sigma, St. Louis, MO, USA). For survival experiments, mice were killed when the rectal temperature would drop $<26^{\circ} \mathrm{C}$. Sera were prepared by standard procedures.

Macrophages. Whole bone marrow was differentiated to macrophages (BMDM) in the presence of macrophage colony-stimulating factor (416- ML, R\&D, Minneapolis, MN, USA). The R8 media (R8 - RPMI 1640 with 8\% fetal bovine serum and $50 \mu \mathrm{M} \beta$-Mercaptoethanol) was changed every second day, and the floater cells were discarded. The macrophages were used for experiments between day 7 and day 9 and were plated at $10^{6} \mathrm{cell} / \mathrm{s} / \mathrm{ml}$. Reagents used were: LPS (from E. coli 0111:B4, L3024, Sigma), TNF $\alpha$ (410-MT, R\&D), IFN $\beta$ (12400-1, PBL Interferon, Piscataway, NJ, USA), zVAD-fmk (627610, Millipore, Billerica, MA, USA), BP (S7015, Selleckchem, Cedarlane, Burlington, ON, Canada), SMAC 164 (gift from Shaomeng Wang), Nec-1 (9037, Sigma), and Nec1s (gift from Dr. Katey Rayner, University of Ottawa). MTT (1-(4,5-dimethylthiazol-2-yl)-3,5-diphenylformazan) assay was performed as described earlier. ${ }^{14}$

Cytokine and chemokine measurements. Cytokines were measured using commercial kits: IL-1 $\beta$ (559603, BD OptEIA, San Diego, CA, USA), IL-12 (p70) (555256, BD OptEIA), IL-10 (555252, BD OptEIA), IL-6 (14-7061, 13-7062, eBioscience), IL-1 $\alpha$ (16-7011, 13-7111, eBioscience, San Diego, CA, USA), and CBA from BD was used for TNF $\alpha$, (558299; BD, San Diego, CA, USA). Chemokines were measured by CBA from BD (MIP-1 $\alpha, 558449$, RANTES, 558345).

Western blotting. BMDMs at the end point of treatment were washed twice with PBS and lysed in RIPA buffer in the presence of protease inhibitors (04693159001, Roche, Mannheim, Germany) and cocktail of phosphatase inhibitors (P5726, Sigma Aldrich) while on ice. Total protein per sample was estimated by the Micro BCA Kit (Thermo Scientific Pierce, cat. number: 23235, Rockford, IL, USA) and continued with the standard western blotting procedure. The samples were mixed with Laemmli loading buffer and heat denaturated at $95^{\circ} \mathrm{C}$ for 5 min and then separated by Laemmli-Discontinuous SDS-PAGE in SDS-TRIS-Glycine buffer, $\mathrm{pH}$ 8.8. The protein transfer to a PVDF membrane was carried out in TRIS-GlycineMethanol buffer. With exception for samples prepared for detecting RIPK1 and RIPK3, where BMDMs were directly lysed in $1 \times$ Laemmli loading buffer while on ice without previous washing steps and continued as above. In addition, cells prepared for MLKL western blotting after the washing steps were lysed in M2 buffer (20 mM Tris, pH 7, 0.5\% NP40, $250 \mathrm{mM} \mathrm{NaCl}, 3 \mathrm{mM}$ EDTA, $3 \mathrm{mM}$ EGTA and $50 \mathrm{mM} \mathrm{NaF}$ ) supplemented with protease and phosphatase inhibitors as above. The samples were mixed in sample buffer (161-0737, Bio-Rad, Hercules, CA, USA) in non-reducing condition (without $\beta$-Mercaptoethanol). Samples lysed in M2 buffer were separated by same procedures as above for RIPA-prepared samples. Antibodies used were: anti-p65 (8242, Cell Signaling, Danvers, MA, USA), antiSAPK/JNK (9258, Cell Signaling), anti-phospho-SAPK/JNK (4668, Cell Signaling), anti-p-p65 (3033, Cell Signaling), anti-caspase 3 (sc-7148, Santa Cruz, Dallas, TX, USA), anti-RIPK1 (610458, BD), anti-RIPK3 (2283, ProSci Inc., Poway, CA, USA), anti-actin (sc-81178, Santa Cruz), anti-STAT1 (9172, Cell Signaling), anti-p-STAT1 S727 (9167, Cell Signaling), anti-caspase 8 (ALX-804-447-C100, Enzo, Farmingdale, NY, USA), anti-MLKL (MABC604, EMD Millipore, Billerica, MA, USA) and anti-cIAP1/2 (CY-P1041, CycLex, Ina, Japan). Densitometric analysis was performed with the GE Healthcare ImageQuantTL software (Piscataway, NJ, USA). Dephosphorylation of the total protein was performed with 50U of Alkaline Phosphatase, Calf Intestinal - CIP, (M0290, NEB, Ipswich, MA, USA) in RIPA-EDTA free, supplemented with protease inhibitors but not phosphatase inhibitors, and $1 \mathrm{x}$ CutSmart NEB buffer.

Immunoprecipitation and mass spectrometry. BMDMs were treated for $3 \mathrm{~h}$ with LPS/ZVAD or TNF $\alpha / \mathrm{ZVAD}$ before proceeding with immunoprecipitation. Anti-RIPK1 (610458, BD) antibody was coupled to Dynabeads (14321D, Life Technologies, Carlsbad, CA, USA) per the manufacturer's instructions. The elute of the immunoprecipitation reaction was analyzed by mass spectrometry (SPARC BioCentre, The Hospital for Sick Children, Toronto, ON, Canada).
Caspase 8 activity assay. The Caspase-Glo 8 Luminescence Kit from Promega (G8200, Madison, WI, USA) was used to assess the caspase 8 activity. The BMDMs were plated in 96-well plate at $10^{6} \mathrm{cell} / \mathrm{s} / \mathrm{ml}$ and handled as indicated in the corresponding figures, caspase 8 inhibitor (C8I) - (zIETD-fmk, 1064-20C, BioVision, Milpitas, CA, USA).

Salmonella infection. ST SL1344 (or ST) was grown in $\mathrm{BH}$ broth to $\mathrm{OD}_{600 \mathrm{~nm}}$ $0.8-0.9$ and $1 \mathrm{ml}$ aliquots were frozen at $-80^{\circ} \mathrm{C}$ in $20 \%$ glycerol-BHI broth. Colony-forming units (CFU) were assessed and used to start infection at the desired multiplicity. For BMDM infection, first the bacteria were washed twice in a room temperature R8 media, then added to the 96- or 24-well plated macrophages and spun for $10 \mathrm{~min}$ at $400 \times \mathrm{g}$ at room temperature and placed at $37^{\circ} \mathrm{C}$ in a humidified $\mathrm{CO}_{2}$ incubator. After $45 \mathrm{~min}$, the extracellular bacteria were washed 3 times for 96 well plates or 5 times for 24-well plates with room temperature R8 media supplemented with gentamycin at $50 \mu \mathrm{g} / \mathrm{ml}$. After additional $2 \mathrm{~h}$ of infection, the macrophages were washed again in R8 with gentamycin at $10 \mu \mathrm{g} / \mathrm{ml}$; this time the infection was carried on until the desired end point. For in vivo tail vein infection, the frozen stock was thawed and washed in ice-cold $0.89 \% \mathrm{NaCl}$ solution, and mice were infected with $200 \mathrm{CFU}$ via the lateral tail vein. The mice were age and sex matched. Release of G6PD following cell death was measured by Vybrant Cytotoxicity Assay Kit (V-23111, Invitrogen, Molecular Probes, Eugene, OR, USA) as recommended by the manufacturer. For caspase 8 activity measurements, where appropriate the cells were pretreated for 30 min with $20 \mu \mathrm{M}$ ZVAD or DMSO (as control), after each washing step ZVAD or DMSO was replenished.

Quantitative RT-PCR. Quantitative RT-PCR was performed as described elsewhere. ${ }^{14}$ Briefly, total RNA was isolated using TRlzol reagent (15596-026, Life Technologies). Isolated RNA was reverse transcribed into CDNA with SuperScript IV First-Strand Synthesis System (18091050, Invitrogen) per the manufacturer's instruction. The CDNA was analyzed with SYBR Green (Life Technologies) method performed on an Applied Biosystems 7500 quantitative RT-PCR system (Foster City, CA, USA). The primers used for qPCR are as follows: Rpp30 FW: $5^{\prime}-\mathrm{TG}$ ACGTGGCAAACTTAGGACT-3'; Rpp30 REV: 5'-ATGGCCGTGGTTTCTTCACT-3' (for Ribonuclease P/MRP 30 subunit); RANTES FW: 5'-CTCACCATATGGCTCG GAC-3'; RANTES REV: 5'-CTTGGCGGTTCCTTCGAGT-3'; MIP-1 $\alpha$ FW: $5^{\prime}$ CATATGGAGCTGACACCCCG-3'; MIP- $1 \alpha$ REV: $5^{\prime}$-GTCAGGAAAATGACACCTG GC-3'; IL-10 FW: 5'-GGTTGCCAAGCCTTATCGGA-3'; IL-10 REV: 5'-GGGGAGAA ATCGATGACAGC-3'; IL-1b FW: 5'-TGCCACCTTTTGACAGTGATG-3'; IL-1b REV: 5'-TGATGTGCTGCTGCGAGATT-3'; IL-6 FW: 5'-CACGGCCTTCCCTACTTCAC-3'; IL-6 REV: 5'-TGCAAGTGCATCATCGTTGT-3'; TNF $\alpha$ FW: 5'-ACGTCGTAGCA AACCACCAA-3'; and TNF $\alpha$ REV: 5'-ATAGCAAATCGGCTGACGGT-3'.

Reactive oxygen species. ROS levels in macrophages were measured on a plate reader following infection with ST as described above. Cells were stained with 2',7'-dichlorodihydrofluorescein diacetate (H2DCFDA; D-399, Molecular Probes-Life Technologies) and fluorescence was measured on a microplate reader.

\section{Conflict of Interest}

The authors declare no conflict of interest.

Acknowledgements. This work was supported by grants from the Canadian Institutes of Health Research and Joan Sealy Award for Cancer Research to SS. We thank Yi Yuan Zhou, MD for technical support.

1. Blander JM. A long-awaited merger of the pathways mediating host defence and programmed cell death. Nat Rev Immunol 2014; 14: 601-618.

2. Vanden Berghe T, Linkermann A, Jouan-Lanhouet $S$, Walczak $H$, Vandenabeele $P$. Regulated necrosis: the expanding network of non-apoptotic cell death pathways. Nat Rev Mol Cell Biol 2014; 15: 135-147.

3. Suzanne M, Steller H. Shaping organisms with apoptosis. Cell Death Differ 2013; 20: 669-675.

4. Murphy JM, Silke J. Ars moriendi; the art of dying well - new insights into the molecular pathways of necroptotic cell death. EMBO Rep 2014; 15: 155-164.

5. Kelliher MA, Grimm S, Ishida Y, Kuo F, Stanger BZ, Leder P. The death domain kinase RIP mediates the TNF-induced NF-kappaB signal. Immunity 1998; 8: 297-303.

6. Roderick JE, Hermance N, Zelic M, Simmons MJ, Polykratis A, Pasparakis M et al. Hematopoietic RIPK1 deficiency results in bone marrow failure caused by apoptosis and RIPK3-mediated necroptosis. Proc Natl Acad Sci USA 2014; 111: 14436-14441. 
7. Kaiser WJ, Daley-Bauer LP, Thapa RJ, Mandal P, Berger SB, Huang C et al. RIP1 suppresses innate immune necrotic as well as apoptotic cell death during mammalian parturition. Proc Natl Acad Sci USA 2014; 111: 7753-7758.

8. Ofengeim D, Yuan J. Regulation of RIP1 kinase signalling at the crossroads of inflammation and cell death. Nat Rev Mol Cell Biol 2013; 14: 727-736.

9. Vandenabeele P, Galluzzi L, Vanden Berghe T, Kroemer G. Molecular mechanisms of necroptosis: an ordered cellular explosion. Nat Rev Mol Cell Biol 2010; 11: 700-714.

10. Vucic D, Dixit VM, Wertz IE. Ubiquitylation in apoptosis: a post-translational modification at the edge of life and death. Nat Rev Mol Cell Biol 2011; 12: 439-452.

11. Kaczmarek A, Vandenabeele P, Krysko DV. Necroptosis: the release of damage-associated molecular patterns and its physiological relevance. Immunity 2013; 38: 209-223.

12. Cho YS, Challa S, Moquin D, Genga R, Ray TD, Guildford M et al. Phosphorylation-driven assembly of the RIP1-RIP3 complex regulates programmed necrosis and virus-induced inflammation. Cell 2009; 137: 1112-1123.

13. Upton JW, Kaiser WJ, Mocarski ES. Virus inhibition of RIP3-dependent necrosis. Cell Host Microbe 2010; 7: 302-313.

14. McComb S, Cessford E, Alturki NA, Joseph J, Shutinoski B, Startek JB et al. Type-I interferon signaling through ISGF3 complex is required for sustained Rip3 activation and necroptosis in macrophages. Proc Natl Acad Sci USA 2014; 111: E3206-E3213.

15. Sun L, Cessford E, Alturki NA, Joseph J, Shutinoski B, Startek JB et al. Mixed lineage kinase domain-like protein mediates necrosis signaling downstream of RIP3 kinase. Cell 2012; 148: 213-227.

16. Wang H, Sun L, Su L, Rizo J, Liu L, Wang LF et al. Mixed lineage kinase domain-like protein MLKL causes necrotic membrane disruption upon phosphorylation by RIP3. Mol Cell 2014; 54: 133-146.

17. Hildebrand JM, Tanzer MC, Lucet IS, Young SN, Spall SK, Sharma P et al. Activation of the pseudokinase MLKL unleashes the four-helix bundle domain to induce membrane localization and necroptotic cell death. Proc Natl Acad Sci USA 2014; 111: 15072-15077.

18. Meylan E, Burns K, Hofmann K, Blancheteau V, Martinon F, Kelliher M et al. RIP1 is an essential mediator of Toll-like receptor 3-induced NF-[kappa]B activation. Nat Immunol 2004; 5: 503-507.

19. Kaiser WJ, Upton JW, Mocarski ES. Receptor-interacting protein homotypic interaction motif-dependent control of NF-\{kappa\}B activation via the DNA-dependent activator of IFN regulatory factors. J Immunol 2008; 181: 6427-6434.

20. Berger SB, Kasparcova V, Hoffman S, Swift B, Dare L, Schaeffer M et al. Cutting edge: RIP1 kinase activity is dispensable for normal development but is a key regulator of inflammation in SHARPIN-deficient mice. J Immunol 2014; 192: 5476-5480.

21. Takahashi N, Duprez L, Grootjans S, Cauwels A, Nerinckx W, DuHadaway JB et al. Necrostatin-1 analogues: critical issues on the specificity, activity and in vivo use in experimental disease models. Cell Death Dis 2012; 3: e437.

22. Newton K, Dugger DL, Wickliffe KE, Kapoor N, de Almagro MC, Vucic D et al. Activity of protein kinase RIPK3 determines whether cells die by necroptosis or apoptosis. Science 2014; 343: 1357-1360.

23. Vince JE, Pantaki D, Feltham R, Mace PD, Cordier SM, Schmukle AC et al. TRAF2 must bind to cellular inhibitors of apoptosis for tumor necrosis factor (tnf) to efficiently activate nf\{kappa\}b and to prevent tnf-induced apoptosis. J Biol Chem 2009; 284: 35906-35915.

24. Dannappel M, Vlantis K, Kumari S, Polykratis A, Kim C, Wachsmuth L et al. RIPK1 maintains epithelial homeostasis by inhibiting apoptosis and necroptosis. Nature 2014; 513: 90-94.

25. Wen Z, Zhong Z, Darnell JE Jr. Maximal activation of transcription by Stat1 and Stat3 requires both tyrosine and serine phosphorylation. Cell 1995; 82: 241-250.

26. Wesemann DR, Benveniste EN. STAT-1 alpha and IFN-gamma as modulators of TNF-alpha signaling in macrophages: regulation and functional implications of the TNF receptor 1: STAT-1 alpha complex. J Immunol 2003; 171: 5313-5319.

27. Hu Y, Park-Min KH, Yarilina A, Ivashkiv LB. Regulation of STAT pathways and IRF1 during human dendritic cell maturation by TNF-alpha and PGE2. J Leukoc Biol 2008; 84: 1353-1360.

28. Wajant $\mathrm{H}$, Pfizenmaier $\mathrm{K}$, Scheurich $\mathrm{P}$. Tumor necrosis factor signaling. Cell Death Differ 2003; 10: 45-65.

29. McComb S, Cheung HH, Korneluk RG, Wang S, Krishnan L, Sad S et al. cIAP1 and cIAP2 limit macrophage necroptosis by inhibiting Rip1 and Rip3 activation. Cell Death Differ 2012; 19: 1791-1801.

30. Dillon CP, Weinlich R, Rodriguez DA, Cripps JG, Quarato G, Gurung P et al. RIPK1 blocks early postnatal lethality mediated by caspase-8 and RIPK3. Cell 2014; 157: 1189-1202.

31. Newton K, Sun X, Dixit VM. Kinase RIP3 is dispensable for normal NF-kappa Bs, signaling by the B-cell and T-cell receptors, tumor necrosis factor receptor 1 , and Toll-like receptors 2 and 4. Mol Cell Biol 2004; 24: 1464-1469.

32. Duprez L, Bertrand MJ, Vanden Berghe T, Dondelinger Y, Festjens N, Vandenabeele P. Intermediate domain of receptor-interacting protein kinase 1 (RIPK1) determines switch between necroptosis and RIPK1 kinase-dependent apoptosis. J Biol Chem 2012; 287: 14863-14872
33. Mandal P, Berger SB, Pillay S, Moriwaki K, Huang C, Guo H et al. RIP3 induces apoptosis independent of pronecrotic kinase activity. Mol Cell 2014; 56: 481-495.

34. Galluzzi L, Bravo-San Pedro JM, Vitale I, Aaronson SA, Abrams JM, Adam D et al. Essentia versus accessory aspects of cell death: recommendations of the NCCD 2015. Cell Death Differ 2015; 22: 58-73.

35. Takeda K, Akira S. TLR signaling pathways. Semin Immunol 2004; 16: 3-9.

36. Mihaly SR, Ninomiya-Tsuji J, Morioka S. TAK1 control of cell death. Cell Death Differ 2014; 21: 1667-1676.

37. Lee TH, Shank J, Cusson N, Kelliher MA. The kinase activity of Rip1 is not required for tumor necrosis factor-alpha-induced IkappaB kinase or p38 MAP kinase activation or for the ubiquitination of Rip1 by Traf2. J Biol Chem 2004; 279: 33185-33191.

38. Yarilina A, Park-Min KH, Antoniv T, Hu X, Ivashkiv LB. TNF activates an IRF1-dependent autocrine loop leading to sustained expression of chemokines and STAT1-dependent type I interferon-response genes. Nat Immunol 2008; 9: 378-387.

39. Ventura JJ, Cogswell P, Flavell RA, Baldwin AS Jr, Davis RJ. JNK potentiates TNF. stimulated necrosis by increasing the production of cytotoxic reactive oxygen species. Genes Dev 2004; 18: 2905-2915.

40. Polykratis A, Hermance N, Zelic M, Roderick J, Kim C, Van TM et al. Cutting edge: RIPK1 kinase inactive mice are viable and protected from TNF-induced necroptosis in vivo. J Immunol 2014; 193: 1539-1543.

41. Takahashi N, Vereecke L, Bertrand MJ, Duprez L, Berger SB, Divert T et al. RIPK1 ensures intestinal homeostasis by protecting the epithelium against apoptosis. Nature 2014; 513: 95-99.

42. Moriwaki K, Bertin J, Gough PJ, Chan FK. A RIPK3-caspase 8 complex mediates atypical pro-IL-1beta processing. J Immunol 2015; 194: 1938-1944.

43. Duong BH, Onizawa M, Oses-Prieto JA, Advincula R, Burlingame A, Malynn BA et al. A2O restricts ubiquitination of pro-interleukin-1beta protein complexes and suppresses NLRP3 inflammasome activity. Immunity 2015; 42: 55-67.

44. Glaccum MB, Stocking KL, Charrier K, Smith JL, Willis CR, Maliszewski C et al. Phenotypic and functional characterization of mice that lack the type I receptor for IL-1. J Immunol 1997; 159: 3364-3371.

45. Sarkar A, Hall MW, Exline M, Hart J, Knatz N, Gatson NT et al. Caspase-1 regulates Escherichia coli sepsis and splenic B cell apoptosis independently of interleukin-1beta and interleukin-18. Am J Respir Crit Care Med 2006; 174: 1003-1010.

46. Hagar JA, Powell DA, Aachoui Y, Ernst RK, Miao EA. Cytoplasmic LPS activates caspase11: implications in TLR4-independent endotoxic shock. Science 2013; 341: 1250-1253.

47. Kayagaki N, Warming S, Lamkanfi M, Vande Walle L, Louie S, Dong J et al. Non-canonical inflammasome activation targets caspase-11. Nature 2011; 479: 117-121.

48. Raupach B, Peuschel SK, Monack DM, Zychlinsky A. Caspase-1-mediated activation of interleukin-1beta (IL-1beta) and IL-18 contributes to innate immune defenses against Salmonella enterica serovar Typhimurium infection. Infect Immun 2006; 74: 4922-4926.

49. Miao EA, Leaf IA, Treuting PM, Mao DP, Dors M, Sarkar A et al. Caspase-1-induced pyroptosis is an innate immune effector mechanism against intracellular bacteria. Nat Immunol 2010; 11: 1136-1142.

50. Vince JE, Wong WW, Gentle I, Lawlor KE, Allam R, O'Reilly L et al. Inhibitor of apoptosis proteins limit RIP3 kinase-dependent interleukin-1 activation. Immunity 2012; 36: 215-227.

51. Philip NH, Dillon CP, Snyder AG, Fitzgerald P, Wynosky-Dolfi MA, Zwack EE et al. Caspase8 mediates caspase-1 processing and innate immune defense in response to bacterial blockade of NF-kappaB and MAPK signaling. Proc Natl Acad Sci USA 2014; 111: 7385-7390.

52. Bossaller L, Chiang PI, Schmidt-Lauber C, Ganesan S, Kaiser WJ, Rathinam VA et al. Cutting edge: FAS (CD95) mediates noncanonical IL-1beta and IL-18 maturation via caspase-8 in an RIP3-independent manner. J Immunol 2012; 189: 5508-5512.

53. Man SM, Tourlomousis P, Hopkins L, Monie TP, Fitzgerald KA, Bryant CE. Salmonella infection induces recruitment of Caspase-8 to the inflammasome to modulate IL-1beta production. J Immunol 2013; 191: 5239-5246.

54. Maelfait J, Vercammen E, Janssens S, Schotte P, Haegman M, Magez S et al. Stimulation of Toll-like receptor 3 and 4 induces interleukin-1beta maturation by caspase-8. J Exp Med 2008; 205: 1967-1973.

55. Puri AW, Broz P, Shen A, Monack DM, Bogyo M. Caspase-1 activity is required to bypass macrophage apoptosis upon Salmonella infection. Nat Chem Biol 2012; 8: 745-747.

56. Broz P, Monack DM. Molecular mechanisms of inflammasome activation during microbial infections. Immunol Rev 2011; 243: 174-190.

57. Robinson N, McComb S, Mulligan R, Dudani R, Krishnan L, Sad S. Type I interferon induces necroptosis in macrophages during infection with Salmonella enterica serovar Typhimurium. Nat Immunol 2012; 13: 954-962.

58. Kang S, Fernandes-Alnemri T, Rogers C, Mayes L, Wang Y, Dillon C et al. Caspase-8 scaffolding function and MLKL regulate NLRP3 inflammasome activation downstream of TLR3. Nat Commun 2015; 6: 7515. 